\title{
correspondence
}

\section{Careers for researchers}

SIR,--We feel that your editorial (29 June, page 695) sympathised particularly with the problems of administrators picking their way through the 'minefield' of fixed term contracts and waiver clauses but gave short shrift to the scientists on short term research grants.

Short term grants may be acceptable at a junior level where postgraduate and postdoctoral workers need to move to gain experience but the virtual absence of tenured positions means that, for most, the only escape from the 'holding pattern' will be the dole queue. Consequently, research scientists feel that fixed term contracts will be regarded by the employers as a way out of not only their legal but also their moral obligations. How gratifying it would be to see administrators seeking ways of remedying the dearth of permanent positions rather than searching for loopholes in current legislation. Funds must be made available to develop a career structure for rescarch scientists so that those of proven ability can concentrate on their research without the distractions of imminent redundancy.

The much overstated 'burning out' of scientific minds before retirement was alluded to in your editorial. If this is the reason for permanent positions not being available to research staff why then is it not also applicable to university teaching and administrative staff who, after all, are in the position of assessing the competence of those subject to short-term contracts. No one has questioned the vital role of senior scientists in, for instance, medical research yet neither the grant-giving bodies nor the universities are willing to accept the financial responsibility of establishing a career structure for them.

Research scientists, whose views have been unrepresented for so long, feel extreme anxiety over the implementation of these fixed term contracts and their continuing lack of career structure. We would welcome the views of others concerned about this problem.
J. J. AYres
M. W. RusSELI.
W. HARVEY
H. A. Simmonds
M. KadLuBowsKi

Guy's Hospital Medical School.

London, UK

SIR,--I was very disappointed to find in the editorial pages of Nature (29 June, page 695) a superficial and dismissive treatment of an urgent problem which affects large numbers of people involved in biomedical research.

Your view that the well tried system of employing young people on short-term contracts stimulates research by ensuring movement of people (and ideas) between laboratories, is only applicable where there is a natural progression from postdoctoral to tenured positions. It is generally acknowledged that the expansion of the universities in the sixties combined with recent cutbacks in money available for research, has resulted in the present critical situation where we have a plethora of well qualified, in some cases excellent, research workers in their late twenties and early thirties who have no hope of gaining tenured employment. This situation can obviously be prevented in the future by discouraging young graduates from taking PhDs. However, it is quite a different matter to tell someone in their early thirties to find another career. Such a cavalier attitude represents a total abrogation of responsibility on the part of the establishment, and for those who are not convinced by such arguments, it is also a colossal waste of public money.

It should be remembered that the short term contract system serves two purposes. One is to discourage young scientists who are not suited for research and the second is to ensure that inordinate amounts of money and time are not wasted on unfruitful research projects. Thus the success of a (three year) project grant reflects the aptitude of the tenured grant holder as well as that of the postdoctoral employee. However, it is only the career of the postdoctoral worker which is in jeopardy if the project fails.

Restructuring the careers of non-clinical postdoctoral research workers, giving them an opportunity of security, will not impose constraints on research as your editorial suggests. On the contrary, under the present system there is no freedom to do research, and if this situation is allowed to continue there will one day be no scientists to do research.

MARLENE ROSE

Chester Beatty Research Institute,

London, UK

\section{Morale at BARC}

Sir,--We have read with great interest your report (6 April, page 489) on the proposed transfer of Dr R. Ramanna, Director, Bhabha Atomic Research Centre (BARC), employing nearly 11,000 workers including more than 3,000 scientists and engineers, as Director General of Defence Research and Adviser to the Defence Minister, Government of India. We completely agree with you that the policy of transferring active scientific workers to essentially administrative posts is normally undesirable. However, we feel that your remarks on Dr Ramanna's transfer do not accurately reflect the facts in two respects.

Firstly, it is not entirely correct to say that Dr Ramanna was an active scientist at BARC and would not remain so as Director General of Defence Research The director of BARC coordinates the activities of some 40 divisions with the assistance of several directors of groups and lays down general policy related to various projects and organisational and budgetary matters. These are important and demanding duties and coupled with his other functionsmostly in public relations-they hardly lcave time for active scientific work.

His transfer to the Ministry of Defence, where he would be formulating R\&D policy and coordinating the work of several laboratories does not involve any essential change in the nature of his work. True, it can be argued that the projects to be coordinated and supervised by him in the Defence Ministry have little relevance to his training as a nuclear physicist but this argument loses all of its force if it is remembered that at BARC Dr Ramanna has been coordinating projects in such diverse areas as chemical engineering, agriculture, food technology, reactor technology, lasers, vacuum technology, biology, nuclear medicines, chemistry and metallurgy.

Secondly, the impression given in your article, that Dr Ramanna's transfer was resented by the BARC scientists and other employees, does not reflect opinion, at the centre. In fact, both the employees' union and the officers' association of BARC, which together represent all the 11,000 workers, issued strong statements welcoming the government decision to transfer Dr Ramanna from BARC.

There is absolutely no question of Dr Ramanna's transfer adversely affecting either the morale of the scientists at $\mathrm{BARC}$ or the quality of their work. M. P. SANKaran

BHABHA Atomic Research Centre, Bombay, India

\section{Parkinson's Law}

SIR,--In a letter combining the literary merits of Sir Vivian Fuchs and William Shakespear (15 June, page 486), it is suggested that $I$ failed to distinguish administrators and non-scientist staff who are not administrators in my analysis of the proportion of scientists in NERC research bodies (18 May, page 184). In fact, my argument is as follows: as a corollary of Parkinson's Law, the proportion of administrators in an organisation will increase with the size of that organisation, and therefore the proportion of non-scientists will increase.

The British Antarctic Survey, as Sir

Vivian points out, is unique; but so is every other scientific organisation. When testing predictions about general laws we are interested in what these organisations have in common, not with differences amongst them. To ensure the objectivity of any comparison, it is necessary to ensure that the facts used are comparable in origin. This I did by deriving information about each organisation from exactly the same source, the NERC report for 1976-77. I was aware that the BAS runs ships, aircraft and field stations-but to have "corrected" the available data to allow for these would have been to treat the BAS differently from the other, equally Bnique, component bodies of NERC.

Nonetheless, if we accept Sir Vivian's plea that the BAS is a special case and exclude it from the analysis we get an exuation very similar to the original:

$$
A=17.84 \log S \cdot 1.31 D-2.26
$$

where $\mathrm{A}$ is the percentage of non-scientists in an organisation, $\mathrm{S}$ the total staff and $D$ the number of addresses. This regression accounts for 73 " of the variation and again both coeflicients are statistically significant. Parkinson's Law is validated irrespective of whether we consider the Britsh Antarctic Survey or not.

Banchory, UK 